\title{
Optically transparent bionanofiber composites with low sensitivity to refractive index of the polymer matrix
}

\section{$\operatorname{AUTHOR}(\mathrm{S})$ :}

Nogi, Masaya; Handa, Keishin; Nakagaito, Antonio Norio

\section{CITATION:}

Nogi, Masaya ... [et al]. Optically transparent bionanofiber composites with low sensitivity to refractive index of the polymer matrix. Applied Physics Letters 2005, 87(24): 243110.

\section{ISSUE DATE:}

2005-12

URL:

http://hdl.handle.net/2433/84902

\section{RIGHT:}

c 2005 American Institute of Physics. 


\title{
Optically transparent bionanofiber composites with low sensitivity to refractive index of the polymer matrix
}

\author{
Masaya Nogi ${ }^{\text {a) }}$ \\ International Innovation Center, Kyoto University, Nishikyo-ku, Kyoto 606-8501, Japan \\ Keishin Handa \\ Mitsubishi Chemical Group Science and Technology Research Center, Mitsubishi Chemical Corporation, \\ Yokohama, Kanagawa 227-8502, Japan \\ Antonio Norio Nakagaito \\ Research Institute for Sustainable Humanosphere, Kyoto University, Uji, Kyoto 611-0011, Japan \\ Hiroyuki Yano \\ Research Institute for Sustainable Humanosphere, Kyoto University, Uji, Kyoto 611-0011, Japan
}

(Received 9 June 2005; accepted 19 October 2005; published online 7 December 2005)

\begin{abstract}
Transparent polymers were reinforced by bacterial cellulose (BC) nanofibers, which are 10 $\times 50 \mathrm{~nm}$ ribbon-shaped fibers. They exhibited high luminous transmittance at a fiber content as high as $60 \mathrm{wt} \%$, and low sensitivity to a variety of refractive indices of matrix resins. Due to the nanofiber size effect, high transparency was obtained against a wider distribution of refractive index of resins from 1.492 to 1.636 at $20^{\circ} \mathrm{C}$. The optical transparency was also surprisingly insensitive to temperature increases up to $80{ }^{\circ} \mathrm{C}$. As such, BC nanofibers appear to be viable candidates for optically transparent reinforcement. (C) 2005 American Institute of Physics.
\end{abstract}

[DOI: $10.1063 / 1.2146056]$

Mechanical reinforcement of optically transparent resins is of significant interest to the optoelectronics industry due to the rapid expansion of related devices, such as displays. Epoxy resins reinforced with micro-sized glass particles or fibers have been successful in obtaining high strength and low thermal expansion with very low loss of transparency. ${ }^{1-7}$ However, in microsized reinforcement composites, the refractive indices of reinforcements and resins must be matched at least to the third decimal place to prevent light scattering, ${ }^{3-5}$ which in practice is a critical disadvantage. Even if the refractive indices of resins and reinforcements are accurately matched, the temperature dependency of the resin's refractive index makes the composites opaque or nontransparent as a result of temperature variations. ${ }^{3,6,7}$ Moreover, because mismatching of the refractive index is emphasized as the reinforcement volume fraction is increased, ${ }^{1,3,4,6}$ the addition of large volume fractions of reinforcement-in order to improve the mechanical properties-presently results in a drastic loss of transparency. ${ }^{1,2}$

In this context, nanosized fibers are considered to be ideal reinforcements, since elements with diameters less than one-tenth of the visible light wavelength are free from light scattering, ${ }^{8}$ as we have already demonstrated experimentally. ${ }^{9}$ In the previous study, we obtained transparent composites reinforcing various types of resins, even at fiber contents as high as $70 \mathrm{wt} \%$, using bacterial cellulose (BC) nanofibers $10 \mathrm{~nm}$ thick and $50 \mathrm{~nm}$ wide (Fig. 1). Because BC nanofibers are bundles of semicrystalline-extended cellulose chains, the resulting nanocomposites are not only highly transparent, but also exhibit a low thermal expansion coefficient comparable to the silicon crystal, and the mechanical strength is five times that of engineered plastics. ${ }^{9}$

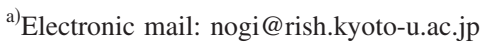

In this letter, we demonstrate that the optical transparency of bionanofiber composites can show very low dependency of the refractive index of resins, even at fiber contents as high as $60 \mathrm{wt} \%$. We thus show the feasibility of using $\mathrm{BC}$ nanofibers as reinforcements in optically transparent materials.

BC pellicles were a kind gift from Dr. Y. Kuwana (Fujicco Co., Ltd.). The bacterial strain Acetobacter xylinum FF-88 was incubated for 10 days in a static culture containing 5\% (V/V) coconut milk (nitrogen content: $0.8 \%$, lipid: $30 \%)$ and $8 \%(\mathrm{~W} / \mathrm{V})$ sucrose, adjusted to $p \mathrm{H} 3.0$ by acetic acid. The $\mathrm{BC}$ fiber content in the pellicles was approximately $1 \%(\mathrm{~V} / \mathrm{V})$. BC pellicles with a thickness of $10 \mathrm{~mm}$ were boiled in $2 \% \mathrm{NaOH}$ for $2 \mathrm{~h}$ in order to remove the bacterial cell debris. The residue was thoroughly washed under running tap water for 2 days and then pressed at $2 \mathrm{MPa}$ and $120^{\circ} \mathrm{C}$ for 4 min to completely remove the water bulk. The $\mathrm{BC}$ sheet thus obtained was $30 \mathrm{~mm} \times 40 \mathrm{~mm}$ and $40 \pm 2 \mu \mathrm{m}$ thick.

The BC sheets were impregnated with neat acrylic resins (type A600, ATMP, TCDDMA, ABPE10, KYO02, KYO01,
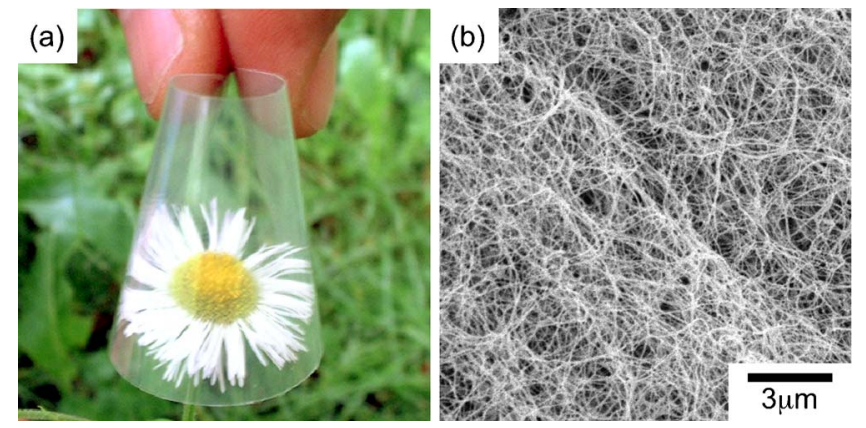

FIG. 1. (Color online) A high transparency BC nanocomposite (a) and a scanning electron micrograph of the $\mathrm{BC}$ nanofiber network (b). 
TABLE I. Refractive indices of acrylic resin sheets $60 \mu \mathrm{m}$ thick at 589.3 nm and $20{ }^{\circ} \mathrm{C}$.

\begin{tabular}{lc}
\hline \hline Resin type & Refractive index \\
\hline A600 & 1.492 \\
ATMP & 1.520 \\
TCDDMA & 1.532 \\
ABPE10 & 1.536 \\
KYO 02 & 1.556 \\
KYO 01 & 1.561 \\
ABPE300 & 1.570 \\
UV3000A & 1.597 \\
UV1000A & 1.636 \\
\hline \hline
\end{tabular}
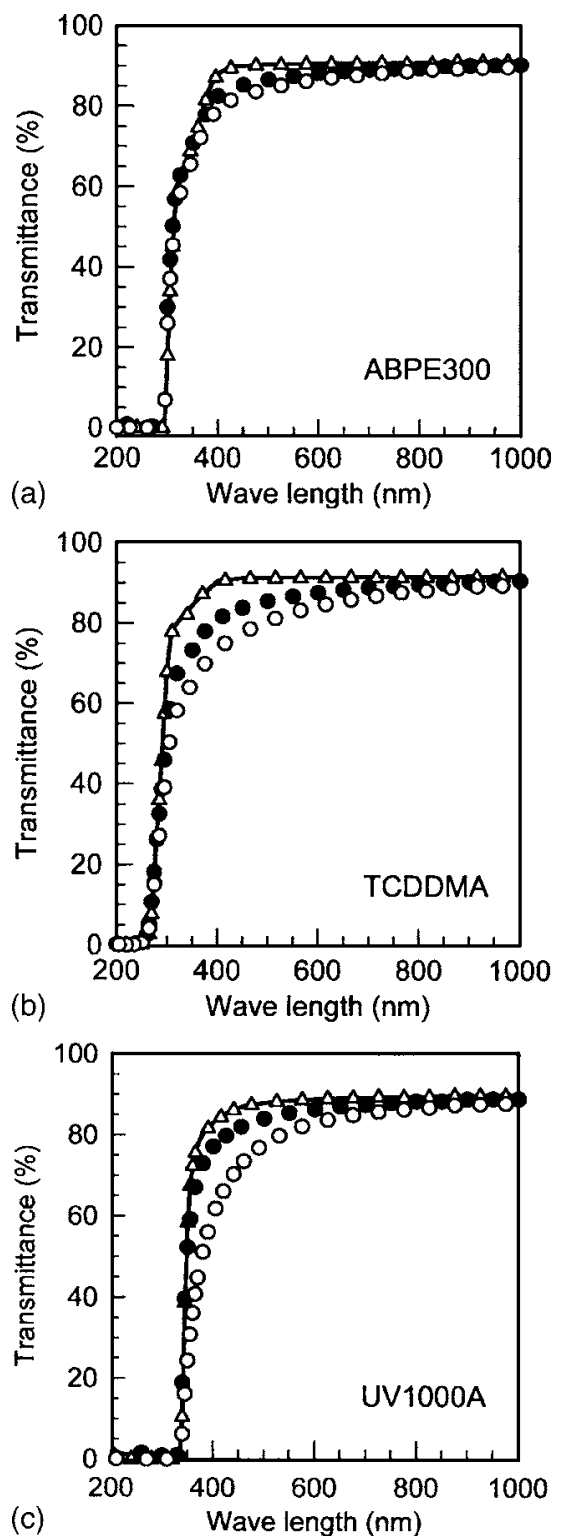

FIG. 2. Luminous transmittance spectra of the BC nanocomposite sheet and the neat acrylic sheet at $20^{\circ} \mathrm{C}$. The filled $(\bullet)$ and open $(\bigcirc)$ symbols show the total and regular transmittance of the $\mathrm{BC}$ nanocomposite sheet, respectively. The solid line (-) and triangle symbols $(\triangle)$ show the total and regular transmittance of the neat acrylic sheet, respectively. (a) ABPE300 acrylic sheet (60 $\mu \mathrm{m}$ thick) and BC nanocomposite sheet (62 $\mu \mathrm{m}$ thick, $60 \mathrm{wt} \%$ ); (b) TCDDMA acrylic sheet $(60 \mu \mathrm{m}$ thick) and a BC nanocomposite sheet (56 $\mu \mathrm{m}$ thick, $62 \mathrm{wt} \%)$; and (c) UV1000A acrylic sheet (60 $\mu \mathrm{m}$ thick) and a BC nanocomposite sheet ( $63 \mu \mathrm{m}$ thick, $57 \mathrm{wt} \%)$. All percentages refer to

UV1000A neat acrylic sheet and BC nanocomposite.
fiber content.
Downloaded 24 Aug 2009 to 130.54.110.33. Redistribution subject to AIP license or copyright; see http://apl.aip.org/apl/copyright.jsp

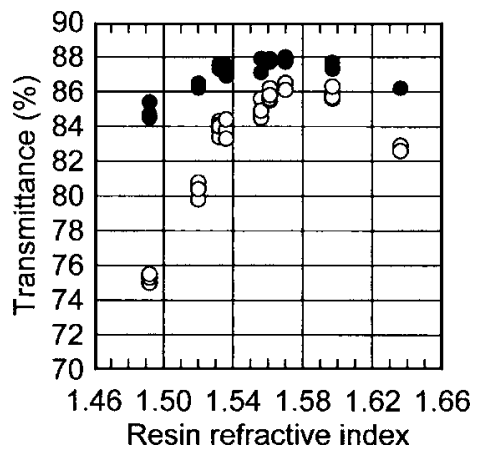

FIG. 3. The total transmittance $(\bullet)$ and regular transmittance $(\bigcirc)$ of $B C$ nanocomposites at $20^{\circ} \mathrm{C}$ and $590 \mathrm{~nm}$ versus the refractive index of their resins at $20^{\circ} \mathrm{C}$ and $589.3 \mathrm{~nm}$.

ABPE300, UV3000A, and UV1000A, Mitsubishi Chemical Corp.) under a reduced pressure of $-0.09 \mathrm{MPa}$ for $12 \mathrm{~h}$. The resin-impregnated $\mathrm{BC}$ sheets were cured using spot ultraviolet (UV) curing equipment (SPOT CURE SP-7, Ushio Inc.) for $8 \mathrm{~min}$ at $40 \mathrm{~mW} / \mathrm{cm}^{2}$. The $\mathrm{BC}$ nanocomposite sheets were 56-63 $\mu \mathrm{m}$ thick, and the fiber content, calculated based on the oven-dry weights of $\mathrm{BC}$ sheets and the $\mathrm{BC}$ nanocomposites, were around 56-62 wt \%. The neat acrylic resin
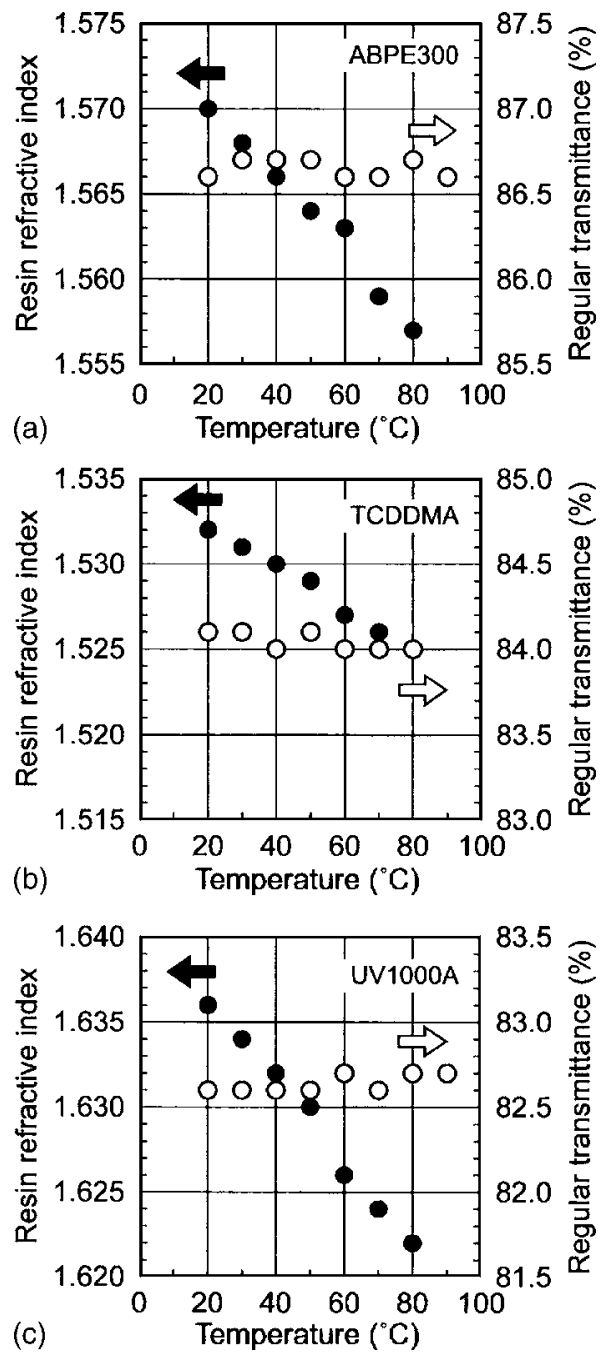

FIG. 4. Temperature dependence of the refractive index of the neat acrylic sheet at $589.3 \mathrm{~nm}(\bullet)$ and the regular transmittance of the BC nanocomposite at $590 \mathrm{~nm}(\bigcirc)$. (a) ABPE300 neat acrylic sheet and BC nanocomposite; (b) TCDDMA neat acrylic sheet and BC nanocomposite; and (c)

UV1000A neat acrylic sheet and BC nanocomposite. 
sheets $60 \mu \mathrm{m}$ in thickness were also prepared under the same curing conditions. Their refractive indices measured at 589.3 $\mathrm{nm}$ and $20^{\circ} \mathrm{C}$ using an Abbe refractometer (T1, Atago Corp.) are displayed in Table I.

The luminous transmittances were measured at wavelengths from 190 to $1000 \mathrm{~nm}$ using a UV-visible nearinfrared spectrometer with an integrating sphere $60 \mathrm{~mm}$ in diameter (U-4100, Hitachi High-Tech. Corp.). The total transmittance and regular transmittance were measured by placing the specimens at the entrance port and at a $25 \mathrm{~cm}$ distance from the entrance port of the integrating sphere, respectively.

Figure 2 shows the luminous transmittance spectra of the neat acrylic resin sheets and the $\mathrm{BC}$ nanocomposite sheets. The BC nanocomposites transmit more than $80 \%$ of the light in the wavelength of 500-800 nm, including surface reflection (Fresnel's reflection). The degradation in luminous transmittances due to nanofiber reinforcement is less than $10 \%$, despite the high fiber content such as $60 \mathrm{wt} \%$. Furthermore, we can see that the difference between the total and regular transmittances of $\mathrm{BC}$ nanocomposites is especially small in the combination with resin type ABPE300. This small difference suggests that the loss of luminous transmittance due to the scattering is also affected by the refractive index differences between the BC nanofiber and resins.

To investigate the dependency of resin refractive index on the transparency of $\mathrm{BC}$ nanocomposites, their luminous transmittances at $590 \mathrm{~nm}$ are compared against the refractive index of resins at $589.3 \mathrm{~nm}$ in Fig. 3. The total and regular transmittances peak at the refractive index around 1.56-1.60, corresponding to the average refractive index of cellulose fiber (1.618 along the fiber and 1.544 in the transverse direction). ${ }^{10}$ Moreover, the total transmittance and the regular transmittance of BC nanocomposites are above $85 \%$ and $75 \%$, respectively, despite the wide distribution of refractive indices from 1.492 to 1.636 . This wide refractive index range of resins enabling high transparency in $\mathrm{BC}$ nanocomposites does extend the variety of polymeric matrixes applicable to optical transparent composites.

The nanofiber size effect in optical transparent composites makes them immune to the large temperature depen- dency of the resin's refractive index, which in practice is a critical disadvantage of transparent microsized reinforcement composites. According to Sato et al., ${ }^{3}$ the increase in temperature from $20{ }^{\circ} \mathrm{C}$ to $100{ }^{\circ} \mathrm{C}$ decreases the refractive index of epoxy resin by 0.01 . The transmittance of composites decreases from $85 \%$ to $20 \%$ due to the mismatch of the refractive indices of resins and reinforcements. Figure 4 shows the temperature dependency of the regular transmittance of $\mathrm{BC}$ nanocomposites and that of the refractive index of the neat acrylic resin. Surprisingly, the regular transmittance of any of the $\mathrm{BC}$ nanocomposites does not change, despite the decrease in the refractive indices of acrylic resins by 0.014 against the elevation in temperature from $20^{\circ} \mathrm{C}$ to $80^{\circ} \mathrm{C}$. This stability of the transmittance clearly expresses that the optical transparency of bionanofiber composites can be independent of temperature over a surprisingly large range of temperature.

In conclusion, the transparency of the $\mathrm{BC}$ nanocomposites was highly insensitive to refractive index of the resin and was independent of the ambient temperature variations. The reinforcement by $\mathrm{BC}$ nanofibers leads the way for a widening of the use of optically transparent polymers in optoelectronic devices.

The authors thank Professor Dr. L. Berglund for helpful discussion. This work was supported by a grant-in-aid from the International Innovation Center, Kyoto University.

${ }^{1}$ T. Naganuma, H. Iba, and Y. Kagawa, J. Mater. Sci. Lett. 18, 1587 (1999).

${ }^{2}$ H. Iba, T. Chang, and Y. Kagawa, J. Composite Sci. Technol. 62, 2043 (2002).

${ }^{3}$ H. Sato, H. Iba, T. Naganuma, and Y. Kagawa, Philos. Mag. B 82, 1369 (2002)

${ }^{4}$ H. Iba and Y. Kagawa, Philos. Mag. B 78, 37 (1998).

${ }^{5}$ S. Kang, D. E. Day, and, J. O. Stoffer, J. Non-Cryst. Solids 220, 299 (1997).

${ }^{6}$ T. Naganuma and Y. Kagawa, J. Mater. Sci. 38, 3103 (2003).

${ }^{7}$ H. Lin, D. Day, K. D. Weaver, and J. O. Stoffer, J. Mater. Sci. 29, 5193 (1994).

${ }^{8}$ B. M. Novak, Adv. Mater. (Weinheim, Ger.) 5, 422 (1993).

${ }^{9}$ H. Yano, J. Sugiyama, A. N. Nakagaito, M. Nogi, T. Matsuura, M. Hikita, and K. Handa, Adv. Mater. (Weinheim, Ger.) 17, 153 (2005).

${ }^{10}$ Polymer Handbook, 4th ed., edited by J. Brandrup, E. H. Immergut, and E. A. Grulke (Wiley, New York, 1999). 